\title{
Osteochondroma of talus and coalition of talocrural and intercuneiform joints - surgical management
}

\author{
Swapnil M. Keny, Kaustubh A. Sawant*, Vijay Singh, Ayush Sharma
}

\begin{abstract}
Department of Orthopaedic Surgery, Dr. B. A. Memorial Central Railway Hospital, Byculla, Mumbai, Maharashtra, India
\end{abstract}

Received: 20 December 2020

Revised: 31 January 2021

Accepted: 01 February 2021

\author{
*Correspondence: \\ Dr. Kaustubh A. Sawant, \\ E-mail: drkaustubhsawant@gmail.com
}

Copyright: ( $)$ the author(s), publisher and licensee Medip Academy. This is an open-access article distributed under the terms of the Creative Commons Attribution Non-Commercial License, which permits unrestricted non-commercial use, distribution, and reproduction in any medium, provided the original work is properly cited.

\begin{abstract}
Osteochondroma of talus is rare benign tumour. Tarsal coalition is a condition in which two or more tarsal bones are joined by non-osseous bridges of cartilage or fibrocartilage or by osseous bridges. Association of Talus osteochondroma with coalition of tarsal bones is extremely rare and has not been reported in the literature before. We are herewith reporting a case of osteochondroma of the talus with coalition of intercuneiform and talocrural joint in an 11-year-old male patient. Patient noticed swelling around ankle and pain on strenuous activities. CT scan confirmed the diagnosis. We did complete extraperiosteal excision of the osteochondroma and resection of tarsal coalition. Histopathological examination confirmed the diagnosis of osteochondroma. At one-year follow-up there is no recurrence of the tumour and patient had full range of motion. Complete extraperiosteal excision of the osteochondroma along with resection of tarsal coalition is important for complete eradication and preventing a recurrence.
\end{abstract}

Keywords: Talus osteochondroma, Tarsal coalition, Foot and ankle, Tumour

\section{INTRODUCTION}

Osteochondroma is a benign bone tumour which is also known as osteocartilaginous exostosis. ${ }^{1-3}$ Talus is a rare location for this tumour and very few cases of the same are reported in literature. ${ }^{4}$

Tarsal coalition is a condition in which two or more tarsal bones are joined either by non-osseous bridges of cartilage or fibrocartilage or by osseous bridges. The most common coalitions are between the calcaneum and the talus or the calcaneum and the navicular bones. The overall incidence of tarsal coalitions is $1.5-6 \% .^{5}$

There has been no case reported with osteochondroma of talus with tarsal coalition. We came across such a case in an 11 years old boy.

\section{CASE REPORT}

The 11-year-old male patient noticed swelling in the ankle for the last 1 year which was slowly growing. The patient was complaining of pain in the ankle joint while running and playing sports. On examination, it was $3 \times 2 \times 2 \mathrm{~cm}$ swelling on the anteromedial aspect of talus, hard in consistency and fixed to the underlying bone without any tenderness.

The range of motion in the ankle \& subtalar joints was restricted. There was no neurovascular deficit. There is no other swelling anywhere in the body. Investigations were done in the form of X-rays which showed bony outgrowth from the talus (Figure 1).

CT scan of ankle was done which showed amorphous bone formation on medial aspect of talus associated with overgrowth of medial part of the lower tibial epiphysis 
with no osseous union between them. Two free bony fragments are seen adjacent to the talar bony overgrowth. These findings are suggestive of medial talocrural joint coalition with fibrous or cartilaginous union.

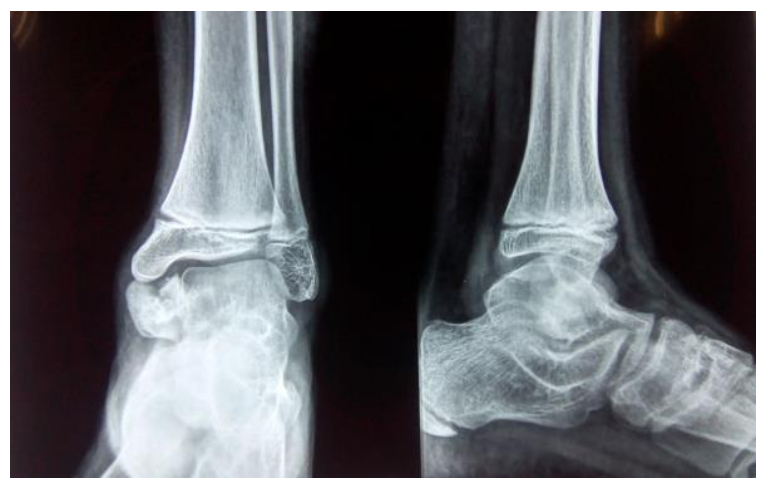

Figure 1: Preop X-ray of the patient.

Small amorphous bony outgrowths are seen over the lateral aspect of medial and intermediate cuneiforms. No osseous bridging is noted between these two bones. A few loose bodies are seen between and superior to the navicular and medial cuneiform. These findings represent intercuneiform joint coalition with fibrous or cartilaginous union (Figure 2).

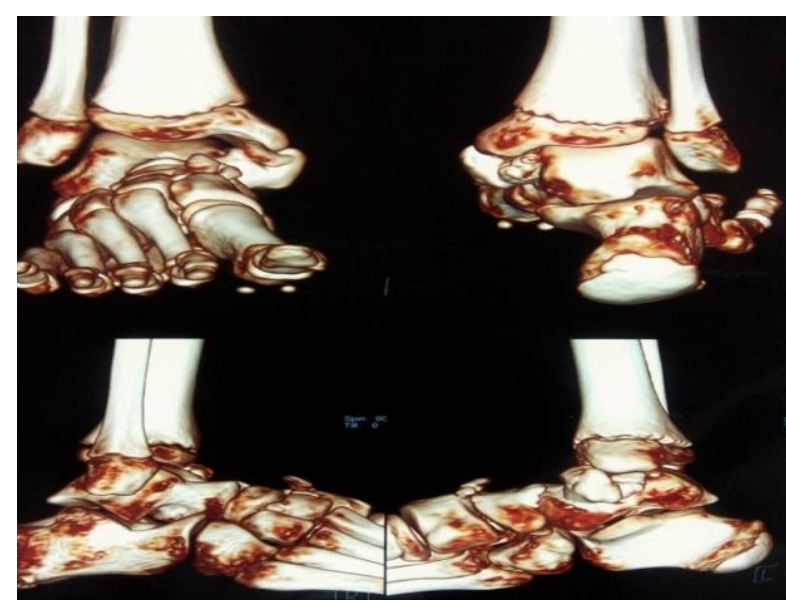

Figure 2: CT scan of ankle and foot with 3D reconstruction.

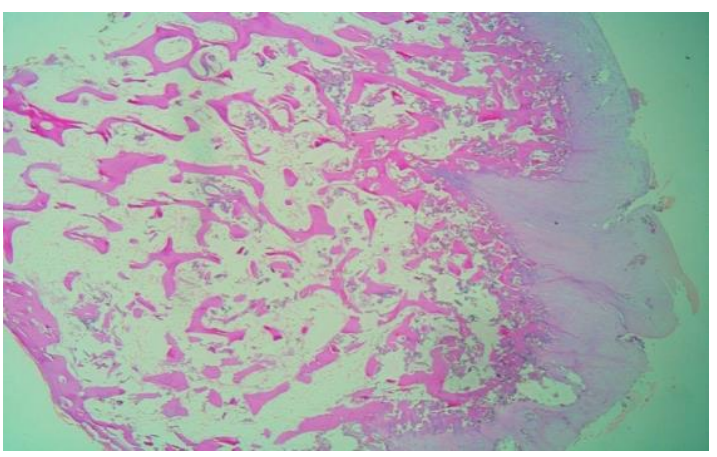

Figure 3: Osteochondroma confirmed on histopathological examination 1x.

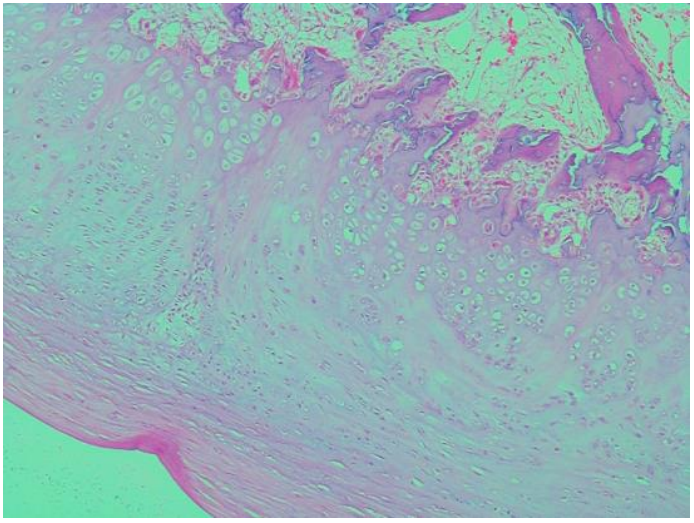

Figure 4: Histopathological examination 10X confirms osteochondroma.

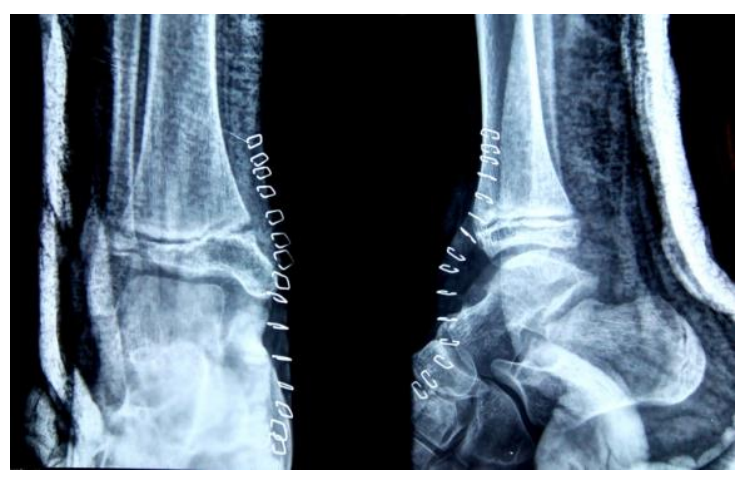

Figure 5: Postop X-ray.

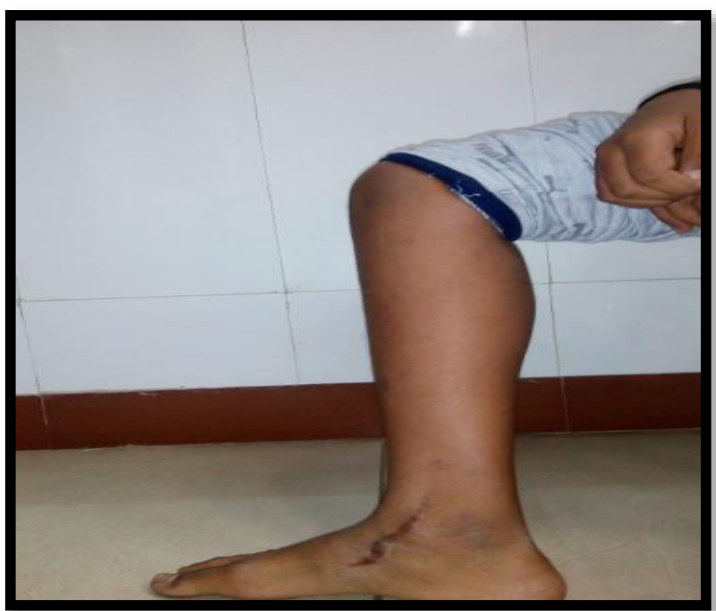

Figure 6: One-year follow-up.

Excisional biopsy done through an anteromedial incision over the ankle, the tumour was exposed all around and the base was clearly exposed. The tumour was excised extraperiosteally and sent for histopathological examination. Loose bony fragments and fibrous tissues between talocalcaneal joint and intercuneiform joints excised.

Histopathological examination confirmed the diagnosis of osteochondroma (Figures 3, 4). Post-op X-ray done (Figure 5). There was not any complication in the 
postoperative period. Ankle range of motion exercises started within a week after slab removal. Weight bearing started as tolerated.

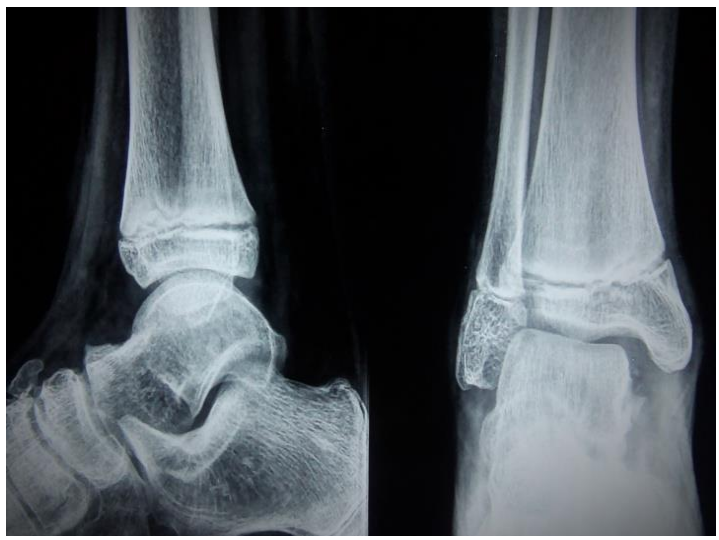

Figure 7: one year followup X-ray.
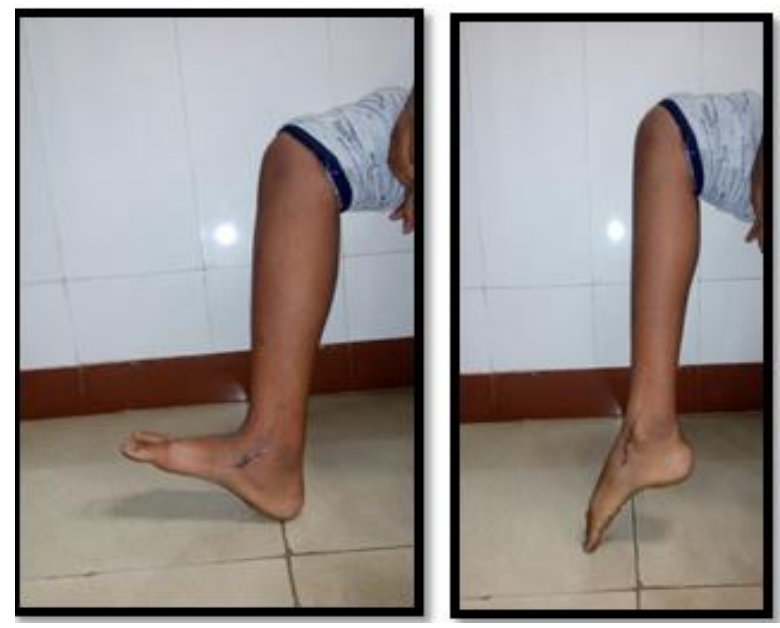

Figure 8: (A and B) Range of motion at one year followup.

Regular follow-ups were done at monthly interval for first 3 months and then at every 3 months. At the follow up of 12 months X-ray showed no evidence of any recurrence (Figures 6,7), patient had good range of motion at ankle and subtalar joints (Figure 8).

\section{DISCUSSION}

An osteochondroma is the most common benign bone tumour. Osteochondromas can occur in any bone that is formed from cartilage. The most common locations are the long bones at the metaphyseal region like proximal humerus, tibia, and distal femur. ${ }^{7}$ It is rarely found in bones of the foot, and is even less common in the talus. ${ }^{8,9}$

Osteochondromas are usually discovered during the first and second decades of life. ${ }^{4}$ However, an osteochondroma in the talus is usually discovered in the third to fifth decades. ${ }^{10-12}$ In this case it was diagnosed in second decade itself.
Association of osteochondroma of talus with coalition of tarsal and talocrural joint has not been reported yet. Tarsal coalition is usually congenital defect that results when adjacent tarsals fail to separate properly during embryonic development. Tarsal coalition may be acquired secondary to post infection, post trauma, post-surgery or with neoplasm. ${ }^{13}$

A solitary osteochondroma is usually asymptomatic. However, an osteochondroma in the talus may present with symptoms like pain, ankle swelling, painless mass and restricted range of ankle motion. ${ }^{7}$ Whereas tarsal coalition presents with restricted range of motion, pain and deformity. ${ }^{14}$ In this case patient presented with ankle swelling and pain.

Radiologically, the talus osteochondroma is seen as a protrusion from the host bone either pedunculated or sessile manner as in the long bone. Computed tomography confirms the diagnosis of the osteochondroma if there is medullary and cortical continuity between the lesion and talar bone. ${ }^{2,4,7,9} \mathrm{CT}$ scan helps in diagnosis and surgical planning of tarsal coalition. ${ }^{14}$

The treatment of an asymptomatic osteochondroma of the talus might be just observation. However, surgical excision is a good treatment method for a symptomatic osteochondroma of the talus. Resection of coalition surgery involves removal of abnormal tissue. ${ }^{13}$ Unlike a simple bony protrusion, an extraperiosteal complete excision is the key to complete eradication and for preventing a recurrence..$^{10}$

\section{CONCLUSION}

In a case of talus osteochondoma with tarsal coalition, complete extraperiosteal excision of osteochondroma with resection of coalition gives good result without any recurrence.

\section{ACKNOWLEDGEMENTS}

The authors thank the parents of the patient and the patient himself for their support and permission to publish this case report. We also like to thank Department of Pathology, Tata Memorial Hospital, Mumbai for their support in the histopathological examinations and providing images of the same.

\section{Funding: No funding sources Conflict of interest: None declared Ethical approval: Not required}

\section{REFERENCES}

1. Chioros PG, Frankel SL, Sidlow CJ. Unusual osteochondroma of the foot and ankle. J Foot Surg 1987;26:407-11.

2. Erler K, Oguz E, Komurcu M, Atesalp S, Basbozkurt M. Ankle swelling in a 6-year-old boy with unusual 
presentation: report of a rare case. J Foot Ankle Surg. 2003;42:235-39.

3. Farrett WD Jr, Stone PA, McGarry JJ. Rare presentation of hereditary multiple exostoses. A case report. J Am Podiatr Med Assoc. 1998;88:135-9.

4. Fuselier CO, Binning T, Kushner D. Solitary osteochondroma of the foot: an in-depth study with case reports. J Foot Surg 1984;23:3-24.

5. Case DT, Burnett SE. Identification of tarsal coalition and frequency estimates from skeletal samples. Int J Osteoarchaeol. 2012;22(6):667-84.

6. Hofmann M, Böni T, Rühl F. Osseous talocalcaneal coalition in a medieval skeleton. Int J Osteoarchaeol. 2010;20(6):623-9.

7. Hanrahan PS, Edelman J, Brash S. Spontaneous hemarthrosis associated with an exostosis of the talus. J Rheumatol. 1987;14:171.

8. Jackson KR, Gurbani B, Otsuka NY. Osteochondromas of the talus presenting as intraarticular loose bodies: report of two cases. Foot Ankle Int. 2004;25:630-1.

9. Joshi D, Kumar N, Singh D, Lai Y, Singh AK. Osteochondroma of the talus in a male adolescent. J Am Podiatr Med Assoc. 2005;95:494-6.
10. Kawai A, Mitani S, Okuda K, Aoki K, Inoue H. Ankle tumor in a 5-year-old boy. Clin Orthop Relat Res. 2003;406:308-16.

11. Keser S, Bayar A. Osteochondroma of the talar neck: a rare cause of callosity the foot dorsum. J Am Podiatr Med Assoc. 2005;95:295-7.

12. Kim S, Chung W, Kim S, Lee W. Osteochondroma of the Talus - A Report of Two Cases. J Korean Orthop Assoc. 2008;43(1):135-8.

13. Kothari A, Masquijo J. Surgical treatment of tarsal coalitions in children and adolescents. EFORT Open Reviews 2020;5(2).

14. Zhou B, Tang K, Hardy M. Talocalcaneal coalition combined with flatfoot in children: diagnosis and treatmen: a review. J Orthop Surg Res. 2014;9:129.

Cite this article as: Keny SM, Sawant KA, Singh V, Sharma A. Osteochondroma of talus and coalition of talocrural and intercuneiform joints - surgical management. Int J Res Orthop 2021;7:420-3. 